\title{
Abstract \\ CuO-Doped Alginate for Simple Electrochemical Vitamin C Sensing in Sweat ${ }^{+}$
}

\author{
Bergoi Ibarlucea ${ }^{1,2, *(\mathbb{D}}$, Arnau Perez Roig ${ }^{1}$, Dmitry Belyaev ${ }^{1}\left(\mathbb{C}\right.$, Larysa Baraban $^{3}$ and Gianaurelio Cuniberti ${ }^{1,2} \mathbb{D}$ \\ 1 Institute for Materials Science and Max Bergmann Center of Biomaterials, Technische Universität Dresden, \\ 01062 Dresden, Germany; arnauperezroig@gmail.com (A.P.R.); dmitry.belyaev@tu-dresden.de (D.B.); \\ gianaurelio.cuniberti@tu-dresden.de (G.C.) \\ 2 Center for Advancing Electronics Dresden (cfaed), Technische Universität Dresden, 01062 Dresden, Germany \\ 3 Helmholtz-Zentrum Dresden-Rossendorf, Institute of Radiopharmaceutical Cancer Research, \\ 01328 Dresden, Germany; 1.baraban@hzdr.de \\ * Correspondence: bergoi.ibarlucea@tu-dresden.de \\ + Presented at the 8th International Symposium on Sensor Science, 17-28 May 2021; Available online: \\ https://i3s2021dresden.sciforum.net/.
}

check for updates

Citation: Ibarlucea, B.;

Perez Roig, A.; Belyaev, D.;

Baraban, L.; Cuniberti, G.

CuO-Doped Alginate for Simple

Electrochemical Vitamin C Sensing in

Sweat. Eng. Proc. 2021, 6, 16.

https: / / doi.org/10.3390/

I3S2021Dresden-10090

Academic Editors: Gianaurelio

Cuniberti and Larysa Baraban

Published: 17 May 2021

Publisher's Note: MDPI stays neutral with regard to jurisdictional claims in published maps and institutional affiliations.

Copyright: (c) 2021 by the authors. Licensee MDPI, Basel, Switzerland. This article is an open access article distributed under the terms and conditions of the Creative Commons Attribution (CC BY) license (https:// creativecommons.org/licenses/by/ $4.0 /)$.

\begin{abstract}
Heat-exposed work activities or prolonged sport sessions suppose a continuous nutrient loss through sweating, leading to long-term health issues. Among prevention steps, the use of miniaturized sensors for real-time monitoring of micronutrient presence directly in sweat can be of great interest. Here, we propose a flexible sensor for the detection of vitamin C (ascorbic acid) based on a very simple process of electrode modification via electrodeposition of a membrane containing $\mathrm{CuO}$ nanoparticles. The reductive effect of ascorbic acid on the nanoparticles produces a shift of the redox peaks in cyclic voltammetry analysis, which can be measured at nearly zero volts as a current increase by amperometry. The detection is performed efficiently at the micromolar ascorbic acid levels found naturally in sweat and works at ultra-low potential $(-5 \mathrm{mV})$, showing no interferences with other typical molecules found in the samples. In combination with sensors for other nutrients, this can be a promising approach for preventive healthcare applications.
\end{abstract}

Keywords: ascorbic acid; vitamin C; electrochemical detection; biosensor; copper oxide nanoparticles

Author Contributions: Conceptualization, B.I., L.B. and G.C.; experimental work, B.I., A.P.R. and D.B.; data analysis, B.I. and A.P.R.; original draft preparation; B.I.; supervision: B.I. and L.B.; project administration, B.I. and G.C.; funding acquisition, G.C. All authors have read and agreed to the published version of the manuscript.

Funding: This research was funded by the Arbeitsgemeinschaft industrieller Forschungsvereinigungen (AiF), grant number F009438.

Conflicts of Interest: The authors declare no conflict of interest. 